\title{
图HAD
}

ISSN-L: 2530-5115

DOI: http://doi.org/10.22585/hospdomic.v2i4.56

\section{DOAJ y su aportación a la transparencia y buenas prácticas en la gestión editorial}

\section{DOA and its contribution to transparency and good practices in editorial management}

\author{
Remedios Melero Melero \\ Miembro del grupo de trabajo Acceso Abierto a La Ciencia \\ Instituto de Agroquímica y Tecnología de Alimentos-CSIC, Valencia, España \\ Correspondencia/Correspondence \\ Remedios Melero Melero \\ rmelero@iata.csic.es \\ Conflicto de Intereses/Competing interest \\ La autora no presenta ningún tipo de conflicto de intereses
}

CÓMO CITAR ESTE TRABAJO | HOW TO CITE THIS PAPER

Melero Melero R. DOAJ y su aportación a la transparencia y buenas prácticas en la gestión editorial. Hosp Domic. 2018;2(4):133-5.

El Directory of Open Access Journals (DOAJ) nació en el año 2003 como un Proyecto de la Universidad de Lund, Suecia. En el año 2013 para garantizar su continuidad y sostenibilidad se creó una empresa sin ánimo de lucro para su gestión con participación de parte de sus creadores originales. Pero no voy a tratar de la sostenibilidad del Directorio, sino del proyecto innovador que supuso en un momento incipiente del movimiento Open Access y que sirvió para identificar revistas cuyos principios ya eran los del acceso abierto. A esto, añadiré que mi visión es la una persona que colabora desde el 2014 como editor de forma voluntaria y altruista, y que ha acumulado una experiencia en cuanto a la revisión del cumplimiento de los criterios DOAJ en revistas que postulan para su inclusión en el directorio.

En 2003 DOAJ apenas tenía 300 revistas en su base de datos y actualmente son más de 12000 los títulos que alberga. El Directorio se creó con unos criterios básicos de incorporación que mostraron ser insuficientes al verificar que algunas de las revistas que decían ser "abiertas" parecían no serlo del todo, o al menos sus políticas editoriales no encajaban con la filosofía con la que había nacido DOAJ. Es decir, la revista debía ser como mínimo de acceso gratuito para el lector, y permitir algún tipo de reutilización de sus contenidos de forma responsable, y en el caso de cobrar por publicar, que se indicara de forma clara y visible en la Web 
de la revista. La posible infiltración de alguna revista predadora, disparó la alerta que desencadenó la elaboración de unos nuevos criterios para la inclusión de revistas y una revisión exhaustiva de su cumplimiento. Los nuevos criterios no tienen en cuenta los contenidos de los artículos, sino las políticas editoriales de las revistas, aunque se exige un número mínimo de artículos publicados en el último año. Las nuevas directrices empezaron a entrar en vigor en el 2014 para aquellas revistas que postularan a partir de ese año, y se dio un plazo de adaptación a aquellas que ya estaban incluidas en el directorio tras el cual se revisaron para ver si cumplían con estos requisitos y mantener su indización.

Digo todo esto porque lo interesante es ver, cómo después de una experiencia de varios años siendo editor/revisor, las revistas que solicitan la inclusión en DOAJ y tenían algunas lagunas conceptuales en torno a las políticas editoriales que aluden a la concepción de cuán abierta es la revista, acerca de los derechos de explotación de los trabajos y del tipo de licencias utilizadas, han podido mejorar su definición y visibilidad gracias al apoyo del equipo de DOAJ.

Dicho esto, ¿cuáles son los criterios [https://bit.ly/2DmU9Sz] que han contribuido a esta mejora en las políticas en las revistas? De toda la información que recaba DOAJ para la inclusión en el directorio [https://bit.ly/2NRAsGo] están los aspectos puramente formales (título, ISSN, URL, editorial, uso de identificadores, entre otros) y otros que afectan a las prácticas editoriales relacionadas con la evaluación de los contenidos, con la definición de la política open access de la revista, y con las licencias de uso de los artículos. De los formales no voy a hacer ninguna referencia significativa, salvo que DOAJ no permite el uso de diferentes dominios web (URLs) para los contenidos propios de la revista (por ejemplo, enlazar a un fichero de instrucciones para autores a un enlace externo al dominio web de la revista). Otro aspecto importante es que cualquier elemento identificativo de la revista o que afecte a los lectores o autores deben estar claramente identificados y expresados (por ejemplo, temática de la revista, instrucciones para el envío de trabajos, instrucciones para los evaluadores, entre otros).

Me centraré en los criterios sobre políticas editoriales de obligado cumplimiento para que la revista sea aceptada. En relación a los criterios de la evaluación (peer review) se pide que el sistema de evaluación esté perfectamente descrito en algún sitio visible y localizable de la web de la revista. Este aspecto contribuye a la transparencia en el proceso editorial, no afecta si el proceso es abierto o si se enmascaran los autores y/o recensores, pero sí que se mencione.

En este sentido, también afecta cómo se lleva a cabo la evaluación, si con evaluadores externos o internos. Si es el equipo editorial quien la hace, debe indicarse y tan solo se permite este sistema en el caso de revistas de arte y humanidades en las que se admite que la puedan hacer entre los miembros del comité editorial. Como el resto de criterios, no vale afirmar qué se hace sino hay que ver dónde se dice y cómo se dice, ahí está la novedad, DOAJ solicita el enlace a través del cual se accede a esta información. A esta, o a cualquier otra que se corresponda con un criterio obligatorio para la inclusión de la revista. Aprovecho esta ocasión para instar a aquellas revistas que utilizan el término "evaluación a ciegas" o "evaluación por pares ciegos" cuando se refieren a la double blind peer review, que revisen su fórmula ya que de acuerdo con el diccionario de la lengua de la RAE, "a ciegas" significa: 1) "ciegamente" y 2) "Sin conocimiento, sin reflexión" y resulta difícil de creer que una evaluación tenga estas características, nada que ver con alguna diversidad funcional o con salvar las barreras de accesibilidad, solo con una mala traducción del término.

Si nos centramos en los criterios que definen "cuán abierta es la revista", por un lado tenemos que es obligatorio definir la política editorial respecto al acceso abierto. No vale decir "soy una revista de acceso abierto" hay que decir dónde y cómo se define su "abierto". En cualquier caso, al menos los artículos deben ser de acceso gratuito desde su publicación (las revistas híbridas no se admiten en DOAJ). Como definición de revista open Access se recomienda utilizar la definición de la Declaración de Budapest "la revista permite a los lectores "leer, descargar, copiar, distribuir, 
imprimir, buscar, o enlazar a los textos completos" de sus artículos y permite a los lectores usarlos para cualquier propósito legal" otra opción sería decir que la revista es de acceso gratuito y qué licencia utiliza para su distribución. En ese sentido DOAJ anima a utilizar licencias abiertas, como por ejemplo las licencias Creative Commons.

En la práctica los editores piensan que con decir que son de acceso abierto es suficiente, y no lo es, en este sentido DOAJ ha hecho que los editores se conciencien del significado del acceso abierto. Con ser gratuitas no es suficiente, sino que se debe decir si se permite una reutilización de los artículos con los fines que se indiquen en la licencia. Otro aspecto importante, y que en la práctica sucede muy frecuentemente, es que se empleen licencias Creative Commons [https://bit. ly/1LkKfeg] y después no se incrusten en los ficheros de los artículos, con lo cual dicha información desparece al descargarse un trabajo.

El hecho de cobrar o no por publicar o por el envío de manuscritos, debe igualmente documentarse a través del enlace donde se diga claramente si se cobra o no y el importe correspondiente. Esto evita situaciones incómodas en las que al autor después de la aceptación de trabajos se les reclame el importe de su publicación.

En resumen, decir quién eres, cómo eres y dónde lo describes es relevante para ser incluido en DOAJ, si además la revista adopta los Principios de Transparencia y Mejores Prácticas en Publicaciones Académicas [https://bit.ly/2xvsKrm] basados en la directrices del Committee on Publication Ethics (COPE) [https://bit.ly/2Ac6uHg], la Open Access Scholarly Publishers Association (OASPA) [https://bit.ly/2NThEGQ] y la World Association of Medical Editors (WAME) [https://bit.ly/2PQXbzL] y los propios de DOAJ, la probabilidad de ser pasar la revisión de los criterios en primera instancia es altamente probable.

Por lo tanto la labor de DOAJ, al igual que otros proyectos como Redalyc, Latindex o SciELO, de los cuales DOAJ se ha nutrido al elaborar los criterios señalados, no solo es la de recopilar y actualizar un índice de revistas de acceso abierto, sino la de difundir buenas prácticas editoriales a través de los profesionales que apoyan este proyecto y que mantienen una correspondencia directa con los editores y directores de las revistas que postulan, y están disponibles para ser consultados. 